\title{
Possible slow slip event beneath the Kii Peninsula, southwest Japan, inferred from historical tilt records in 1973
}

\author{
Masayuki Kano ${ }^{1^{*}}$ (i) and Yasuyuki Kano ${ }^{2}$
}

\begin{abstract}
Recent geodetic measurements have detected recurrent slow slip events (SSEs) in many subduction zones. Numerical simulations suggest that the recurrence intervals and magnitudes of such SSEs decrease in the later stage of the interseismic period. Therefore, activities of SSEs and their temporal variations in recurrence intervals and magnitudes provide important clues for evaluating future large earthquakes. However, our knowledge of recurrent SSEs before the establishment of dense observation networks is limited. Here, we report a possible SSE in 1973 beneath the Kii peninsula along the Nankai subduction zone, southwest Japan, where magnitude 8 class earthquakes such as the 1944 Tonankai and 1946 Nankai earthquakes repeatedly occur. The possible SSE was detected by a horizontal pendulum tiltmeter installed in 1947 at the Kishu observatory. We recovered and converted the original tilt records from 1969 to 1974 drawn on bromide (light sensitive) papers to digital tilt records. In late-November 1973, there was a slow transient signal down to the northeast of about $1.4 \mu \mathrm{rad}$, lasting about 1-3 days. Assuming this crustal deformation was due to an SSE, we searched for a possible fault model by adopting the already-known SSE models occurring from 1996 to 2012 as template models. Among the 42 template fault models, five models were able to qualitatively explain the direction of the observed tilt change. The centroids of these fault models were located about 30-60 km to the west of the observatory. In the source region, two magnitude 5 class earthquakes occurred before the initiation of the transient signal, and thus may be related to the occurrence of the possible SSE. In contrast, the magnitude of the calculated tilt change was about 1-2 order smaller than that of the observed tilt change. This discrepancy could be partly explained by a slip amount larger than that in the template models, which suggests that the possible SSE in 1973 was larger than those detected by recent observations. Further investigation of historical data on crustal deformation will reveal more about the temporal change in the recurrence intervals and magnitudes of SSEs during earthquake cycles of large earthquakes.
\end{abstract}

Keywords: Historical tilt records, Slow slip event, Southwest Japan, Nankai subduction zone, Data preservation

\section{Introduction}

Slow slip events (SSEs) are spontaneous slow fault motions along a subducting plate boundary lasting from days to years (Hirose et al. 1999; Rogers and Dragert 2003). SSEs occur without radiating seismic energy; therefore, geodetic measurements such as tiltmeters, strainmeters and the Global Navigation Satellite System (GNSS) have

\footnotetext{
*Correspondence: masayuki.kano.a3@tohoku.ac.jp

${ }^{1}$ Graduate School of Science, Tohoku University, 6-3, Aramaki-aza-aoba,

Aoba-ku, Sendai 980-8578, Japan

Full list of author information is available at the end of the article
}

contributed to the detection of SSE signals. Recent observations have clarified that SSEs are often observed prior to large earthquakes (Kato et al. 2012; Ito et al. 2013; Graham et al. 2014; Ruiz et al. 2014; Radiguet et al. 2016). SSEs may be related to the occurrence of large earthquakes by transferring tectonic stress at nearby megathrust faults because these SSEs occurred near the source regions.

Numerical studies have recently demonstrated that the recurrence intervals of SSEs decrease in the later part of the interseismic period (Matsuzawa et al. 2010). This indicates that SSEs perturb stress in megathrust faults more frequently prior to coseismic rupture than 
other interseismic periods. In addition, Luo and Liu (2019) found that the peak slip rate and the amount of slip of SSEs decrease before megathrust earthquakes based on a numerical simulation similar to Matsuzawa et al. (2010). Therefore, the activities of SSEs and their variations in time and magnitude provide important clues to anticipated large earthquakes.

SSEs have been detected by dense geodetic observation networks (Szeliga et al. 2008; Sekine et al. 2010; Nishimura et al. 2013; Nishimura 2014; Rousset et al. 2017). For example, Sekine et al. (2010) analyzed tilt records of the high-sensitivity seismograph network (Hi-net), operated by the National Research Network for Earth Science and Disaster Resilience (Okada et al. 2004; Obara et al. 2005), to detect 54 SSEs from 2001 to 2008 in southwest Japan. In contrast, Nishimura et al. (2013) developed a systematic detection method of SSEs based on the GNSS time series. They analyzed the GNSS Earth Observation Network System (GEONET) (Nakagawa et al. 2009) operated by the Geospatial Information Authority of Japan and found more than 100 SSEs from 1996 to 2012 in southwest Japan. In the Mexico subduction zone, Rousset et al. (2017) constructed another systematic detection technique for SSEs, named the geodetic matched filter, to clarify 28 events from 2005 to 2014. These comprehensive studies of SSE detections are largely attributed to dense observation networks such as $\mathrm{Hi}$-net and GEONET, which are available in these few decades.

In contrast, there are few reports of SSEs before the establishment of such dense networks (Kimata et al. 2001; Kobayashi and Yamamoto 2011; Alba et al. 2019). In such a case, traditional geodetic observations such as leveling, tide gauge and electronic distance measurement are useful for detecting possible SSEs. For example, Kobayashi and Yamamoto (2011) utilized leveling and sea level data in western Shikoku, southwest Japan, and found that vertical crustal deformation patterns in 1980, 1985-1986 and 1991 were similar to those found during the 1996-1997 and 2003 SSEs, which were already detected based on GNSS data. They pointed out that such deformations may indicate the possibility of SSE occurrences. Such kinds of traditional geodetic data have the potential to reveal the occurrence of SSEs prior to the establishment of the dense observation network. In this study, we report another possible SSE beneath the Kii Peninsula, southwest Japan (Fig. 1a), in 1973, based on historical tilt records at the Kishu observatory, and attempt to construct a possible source fault model. Then, we investigate the validity of the possible models by comparing the strain changes observed by extensometers at the Kishu observatory (Ozawa 1978) and the related seismic phenomena.

\section{Data}

We used tilt data recorded at the Kishu observatory, southwest Japan (Fig. 1a), operated and preserved by the Disaster Prevention Research Institute, Kyoto University. At the Kishu observatory, horizontal pendulum tiltmeters were installed in 1947 (Tanaka et al. 1981). The original tilt records until at least 1974 were drawn on bromide (light sensitive) papers (Fig. 1b, c) with a length of $30 \mathrm{~cm}$ and height of $8.5 \mathrm{~cm}$, and the recording speed was about $0.2 \mathrm{~cm} / \mathrm{h}$. These bromide papers were stored at the Abuyama Observatory at Kyoto University. The observation period, as well as note for change in recording speed and the occurrence date of the earthquakes, was recorded on the back of the paper. Each bromide paper recorded two components in N57W (top) and N33E (bottom) directions of ground tilt for about 1 week (Fig. 1c). We recovered the data from 1969 to 1974 by digitizing the lines on the bromide papers using the method of Mashiko et al. (2013), and hereafter, focus on the records in late November in 1973 (Periods I-III) spanning three bromide papers (Fig. 1C). Because the original bromide paper was set in a circular arrangement, the records were overdrawn when the observed record reached the end. As a result, there were two tilt record lines in each component for about one-fourth of the paper (Fig. 1c). This sometimes yields to overlap two lines (e.g., $b^{\prime}-c^{\prime}$ and $c^{\prime}-d^{\prime}$ in Fig. 1c), and fails to successfully separate two lines in digitizing the data (solid colored squares in Fig. 1d). For this reason, tilt records at the end of each period (dotted squares in Fig. 1d) in the digitized time series are represented at the initial time of each period (solid squares in Fig. 1d) and there are artificial steps at the start or the end of the overlapping periods (on November 27 in N57W component, and November 20, December 3 and 4 in N33E component). We did not correct these steps because, in such a case, most of the tilt records in the overlapping period (solid squares in Fig. 1d) truly represent the data during the period at the end of each paper (dotted squares in Fig. 1d). Therefore, hereafter, we do not consider the period when two tilt lines were recorded in each component, i.e., the period shown by colored and dotted squares in Fig. 1d. Furthermore, we also ignore the record obtained during the first $\sim 1 \mathrm{~cm}$ of each bromide paper because this record corresponds to the stuck region in circling the bromide paper.

We used the sensitivity value of the tiltmeter of 0.145 $\mu \mathrm{rad} / \mathrm{mm}$, which was originally shown as "ca. $0.03 \mathrm{~s} / \mathrm{mm}$ " in Table 1 in Tanaka et al. (1981). Tidal signals appeared on the record are comparable to theoretical tide calculated using GOTIC2 (Matsumoto et al. 2001) (Fig. 1d). We used the tidal analysis program BAYTAP-G (Tamura et al. 1991) to extract O1 and M2 constituents from the observed tilt record. Amplitudes of observed tilts were 


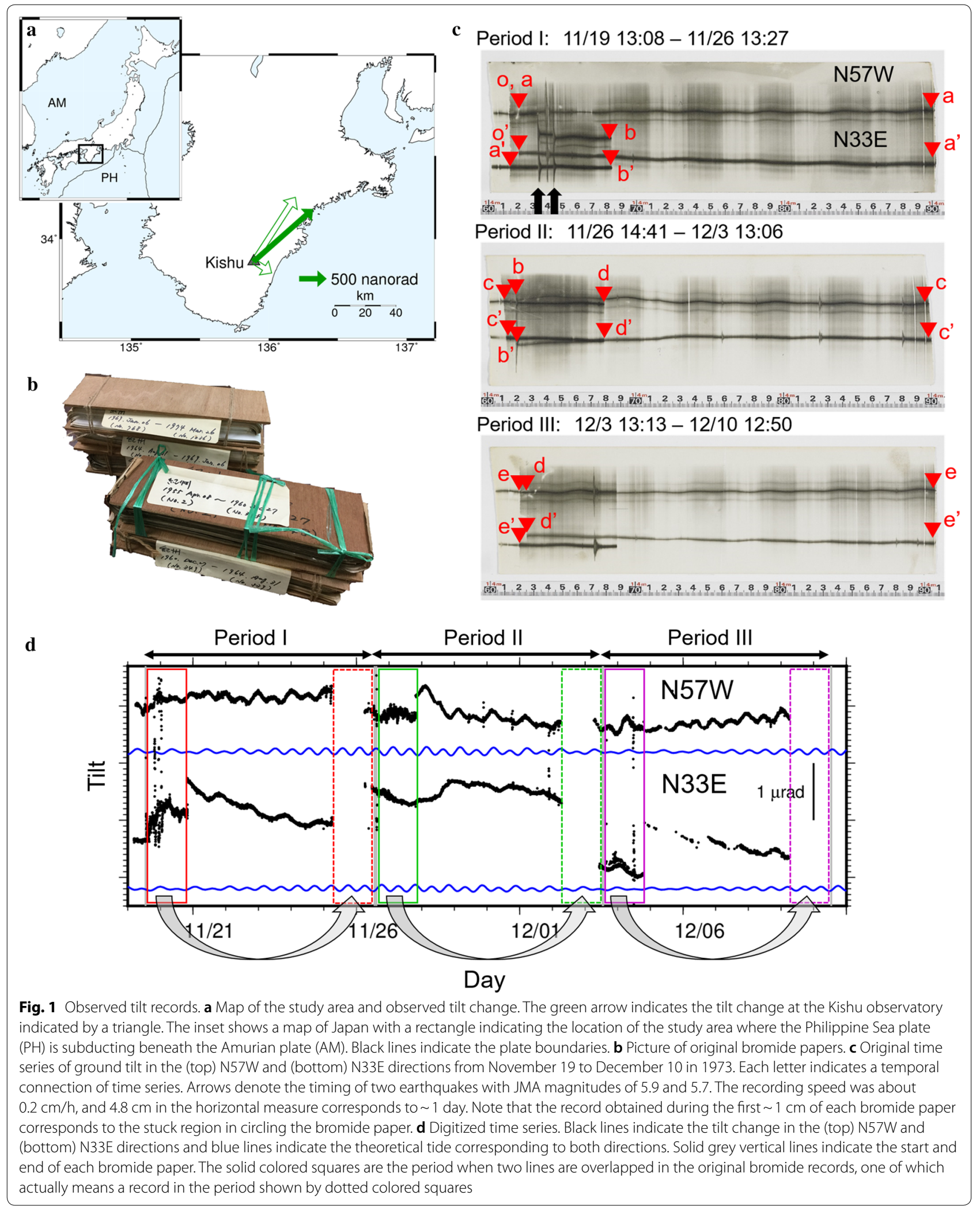


$226 \%$ and $275 \%$ of theoretical tide for O1 in N57W and N33E, and $120 \%$ and $54 \%$ for M2 in N57W and N33E, respectively. There exists a discrepancy between the observed and theoretical amplitude of tidal response probably due to the cavity and topography effects (Harrison 1976). However, we did not correct this discrepancy because it does not significantly affect our main conclusions.

There was a transient signal spanning two bromide papers (Periods I and II) recorded in late November in 1973 (Fig. 1c, d). To define the observed tilt change, we fit a linear function to the tilt data for two components between November 22 and 24, respectively, and extrapolate the linear function to November 29. We also fit a linear function between November 29 and December 1. The observed tilt change was defined as the difference of values of the two linear functions on November 29. Although we assumed that the slopes of two linear functions were different, this assumption does not significantly affect our conclusions. There was a slow tilt change of about $0.4 \mu \mathrm{rad}$ up and about $1.4 \mu \mathrm{rad}$ down to the directions of N57W and N33E, respectively, which lasted about 1-3 days. This transient movement seems to start on November 25. However, we cannot clearly determine the onset of the movement because of the overlapping problem. Ground tilt is sometimes sensitive to rainfall, but because there was little precipitation during this period, the transient signal may represent crustal deformation due to fault slip along the plate boundary.

\section{Fault modeling of an SSE}

Previous studies detected SSEs that continued for a few days beneath the Kii Peninsula at a depth of about $35 \mathrm{~km}$ along the plate boundary between the subducting Philippine Sea plate $(\mathrm{PH})$ and the overriding Amurian plate (AM), and estimated their fault models (Sekine et al. 2010; Nishimura et al. 2013). These SSEs recur with an interval of approximately 6 months in the eastern part of the Kii Peninsula and with a frequency of less than one per year in the western part. In this study, we attempt to construct a possible fault model based on these previous fault models.

First, we adopted the fault models due to 42 SSEs (Models 1-42) from 1996 to 2012 obtained by Nishimura et al. (2013) as template models (see Additional file 1: Table S1). Fault parameters of the template models were determined by the non-linear inversion method (Matsu'ura and Hasegawa 1987) assuming the SSEs occurred along the subducting plate interface and the shapes of the faults were rectangular. Because it is difficult to constrain fault parameters from a single station record, we conducted forward modeling and calculated tilt changes assuming the template models using a formulation for an elastic homogeneous half-space by Okada (1992). Then, we searched for a possible fault model that could qualitatively explain the observed tilt changes at the Kishu observatory in 1973.

\section{Results}

Among the 42 template fault models, 10 models (Models $3,5,6,9,15,22,23,24,32$ and 35) indicate the directions of tilt changes (N49E) in the same quadrant as that of the observed tilt change (Fig. 2 and Additional file 1: Figure S1). It should be noted that the centroids of these fault models all located in the western or southwestern side of the Kishu observatory. Hereafter, we focus on the five models (Fig. 2, Models 5, 6, 23, 24 and 35) that exhibited the discrepancies in the direction between the observed and calculated tilt vectors less than $10^{\circ}$ and refer as possible models. These possible models all indicate that if the observed tilt change was caused by an SSE, the centroids of the faults must be about $30-60 \mathrm{~km}$ west or southwest of the observatory to explain the direction of the observed tilt change. Comparisons between the observed and calculated tilt changes for the other template models are summarized in Additional file 1: Figure S1.

\section{Discussion and conclusions}

We found the possible fault models that could explain the direction of the observed tilt change. However, the calculated tilt changes in the possible models were 1-2 order smaller than the observed tilt change. One possibility is that the slip amount was greater than those in the template models. If the fault location of the 1973 SSE was the same as those of the possible models, the slip amount should be 91, 50, 28, 95 and $128 \mathrm{~cm}$ for Models 5, $6,23,24$ and 35 , respectively. This implies that a fault slip one order larger than that in the possible model is necessary even in the smallest case of Model 23 to explain the observed amplitude. Another possibility is that the location of the 1973 SSE was different from that in the possible models. Figure 3 shows the spatial distributions of tilt changes calculated from the possible models. The amount of tilt change is at most about $100 \mathrm{nrad}$ regardless of the azimuth, which is still one order smaller than the observed amplitude. Although these spatial distributions were obtained assuming the same fault parameters as the possible models, the maximum value of the calculated tilt amplitude does not change significantly as long as the depth, area and slip amount in the assumed fault are similar. This indicates that it is difficult to use the difference in fault location alone to explain the discrepancy between the observed and calculated amplitude of ground tilt. In addition, there may be a possibility of overestimating the observed tilt change. As mentioned in "Data" section, the original tilt records were written on bromide papers 

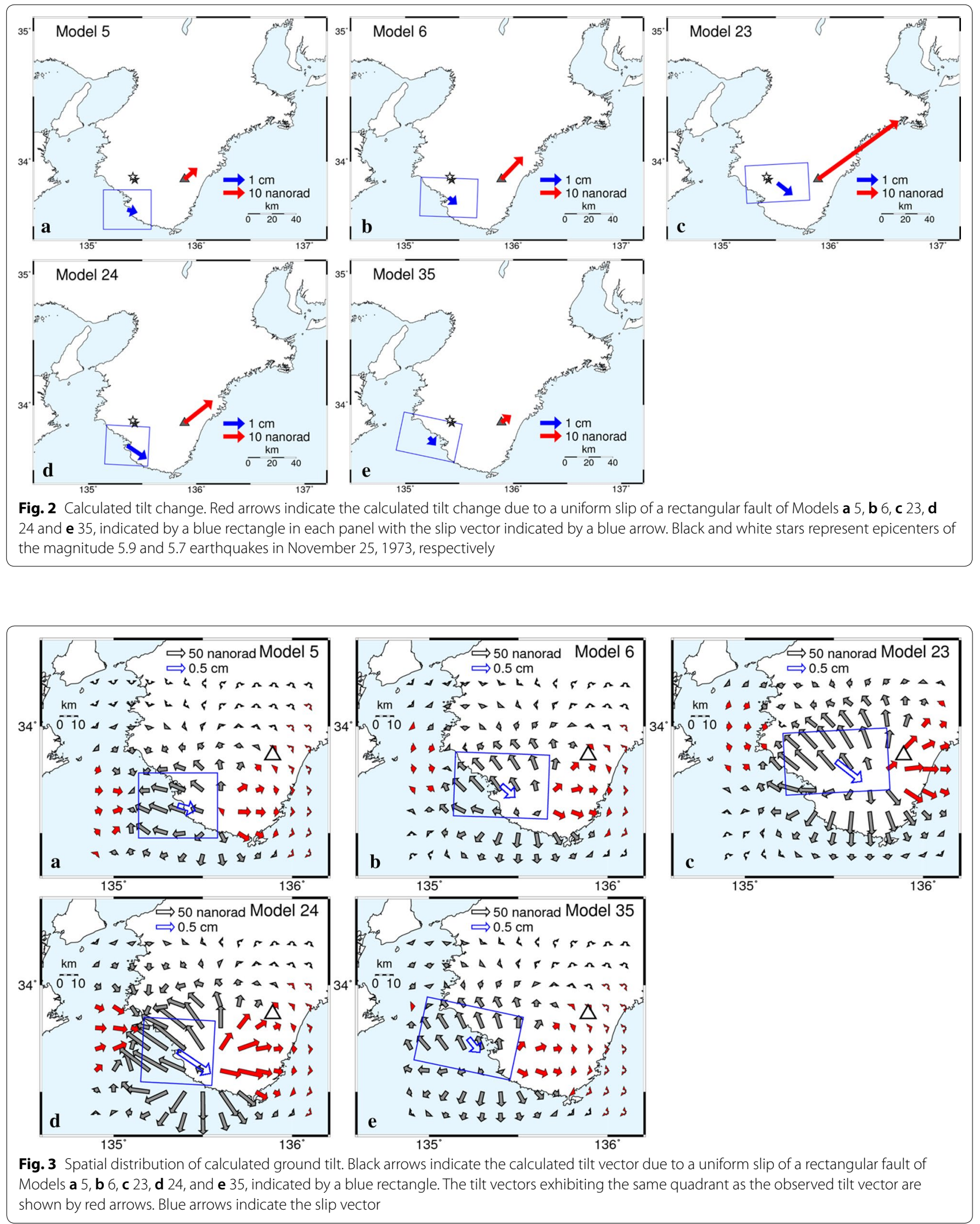
and the transient tilt change spanned two papers. Therefore, if the records in two papers were not correctly connected, it would bias the observed tilt change. However, the latter half of the observed tilt signal was recorded only on a single paper and was thus not affected by the error due to the connection of papers (Fig. 1c, d). This signal was about half of the original observed tilt change and was still larger than those expected from the possible models. Therefore, the overestimation of data alone cannot explain the discrepancy of tilt amplitude, and the combination of the abovementioned possibilities may be necessary to explain the discrepancy.

At the Kishu observatory, extensometers were also operating from 1961. The extensometers recorded a transient strain change of $\sim 4-5 \times 10^{-7}$ contraction in north-south direction (NS) and $\sim 2-3 \times 10^{-7}$ extension in east-west direction (EW) during the possible SSE (Fig. 2 in Ozawa (1978)). We have examined whether the possible fault models determined by tilt records could explain these strain data. Figure 4 summarizes the spatial distributions of strain change calculated by assuming the possible models, indicating that all the possible models could not explain the features of strain data, i.e., the contraction in NS, extension in EW, and the absolute value of strain change in NS is larger than that in EW. All the possible models indicate that the observed features can be reproduced at locations on the northern-northeastern, western, and southern side of the fault, indicated by circles in Fig. 4. On the other hand, the spatial distributions of tilt changes (Fig. 3) show that the directions of tilt vectors at locations on the northeasternnorthwestern side of the fault indicate the same quadrant as that of the observed tilt. Therefore, it may be necessary for a fault to locate on the southwestern side of the observatory to simultaneously explain the observed features of tiltmeters and extensometers. Although additional observation would be required for a fine estimation of fault parameters to reproduce both observed features, the limited data provide a rough constraint of possible fault location beneath the western part of the Kii Peninsula. In addition, it should be noted that the calculated strain change is one order smaller than the observed strain change (Fig. 4) and such feature is indicated by tilt changes as well.

The possible fault models locate in the western part of the Kii Peninsula, where 14 SSEs recurrently occur from 1996 to 2012 corresponding to a frequency of less than one per year on average (Nishimura et al. 2013). We have investigated the bromide tilt records from 1969 to 1974, and do not find any clear transient signal except for the 1973 SSE mentioned in this paper. Although we cannot rule out the possibility that such transient signal was masked by a local meteorological condition, recurrence intervals in 1970s might be longer than those inferred by current dense observations.
The tiltmeter observed seismic waves due to two earthquakes on November 25, 1973 (arrows in Fig. 1c), prior to the initiation of the possible SSE. Tilt steps due to these earthquakes were recorded in N57W component (Fig. 1c). According to the unified hypocenter catalog provided by the Japan Meteorological Agency (JMA), the hypocenters were close to the source regions of the possible SSE models, located about $40 \mathrm{~km}$ west of the Kishu observatory at a depth of $54 \mathrm{~km}$ (Fig. 2) below the oceanic Moho of the PH (Kato et al. 2014). The JMA magnitudes of these earthquakes were 5.9 and 5.7, respectively, which were exceptionally large in this region where only five earthquakes with a magnitude greater than 5.0 were recorded from 1923 to 2014 in the JMA unified hypocenter catalog. The extensometer started to show the transient signal after these earthquakes (Fig. 2 in Ozawa (1978)) and therefore, such large earthquakes may be related to the occurrence of the SSE, potentially through stress perturbation and/or fluid migration.

We recovered the historical bromide records of ground tilt from 1969 to 1974 from the Kishu observatory, southwest Japan. After digitizing the records, we analyzed the transient signal lasting for about 1-3 days in November 1973. Assuming this transient signal was due to an SSE on the plate interface, we inferred possible models among the recent fault models between 1996 to 2012 estimated by Nishimura et al. (2013). All the possible models, located about $30-60 \mathrm{~km}$ west and southwest of the observatory, could qualitatively explain the azimuth of the observed tilt change. However, the amplitude of the calculated tilt was 1-2 order smaller than that of the observed tilt. This discrepancy could be partly explained by the amount of fault slip, fault location and bias due to the connection of bromide papers. In addition, there is a possibility that the recurrence interval in those era was longer compared to the current observations. The SSE was likely related to the two earthquakes, with magnitudes of 5.9 and 5.7, that occurred 1 day before the initiation of the transient signal.

Numerical simulations demonstrate that the slip amount and the recurrence interval of SSEs intrinsically decrease in the later stage of the interseismic period (Luo and Liu 2019). This indicates that if the slip amount due to the 1973 SSE was larger than those in the possible models estimated in the last 20 years and if the recurrence interval around 1973 was longer than that in recent years, the current state may be in the later stage of the interseismic period of the earthquake cycle along the subducting $\mathrm{PH}$, where magnitude 8 class earthquakes such as 1944 Tonankai and 1946 Nankai earthquakes repeatedly occur with intervals of 90-200 years (Ando 1975). Continuous and careful investigation of historical bromide tilt records and 

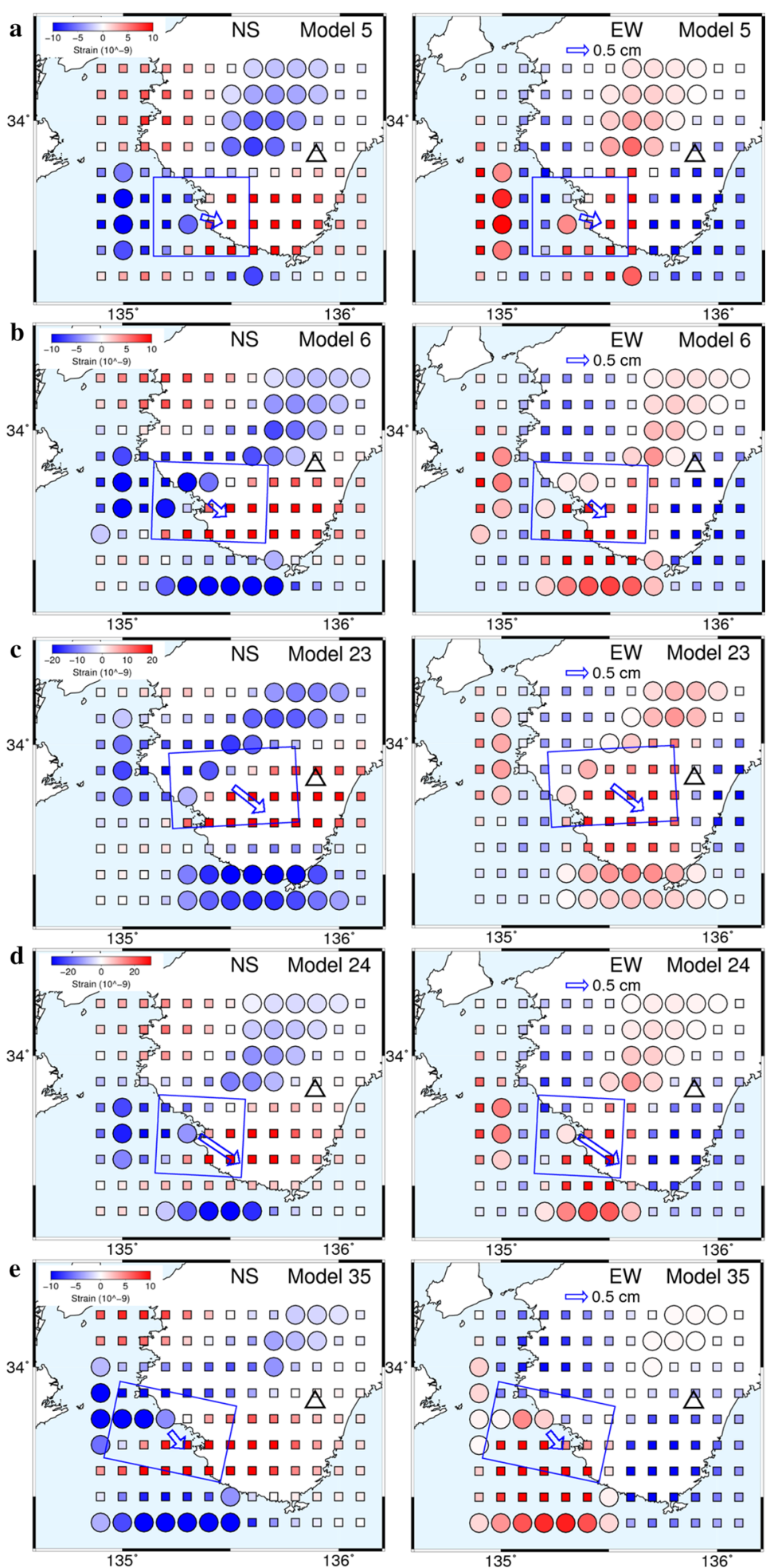

Fig. 4 Spatial distribution of calculated strain. Squares and circles indicate the calculated strain change due to a uniform slip of a rectangular fault of Models a 5, b 6, c 23, d 24, and e 35, indicated by a blue rectangle. Locations in which calculated strain change have the same features of the observed strain data, i.e., the contraction in NS, extension in EW, and the absolute value of strain change in NS is larger than that in EW, are shown by circles. Blue arrows indicate the slip vector 
finding raw records of extensometers will reveal more SSEs and attribute to clarify the temporal change in recurrence interval and magnitude of SSEs.

\section{Supplementary information}

Supplementary information accompanies this paper at https://doi. org/10.1186/s40623-019-1076-9.

Additional file 1: Table S1. Fault model parameters of SSEs in southwest Japan estimated by Nishimura et al. (2013). Figure S1. Calculated tilt change for all fault models. Red arrows indicate the calculated tilt change due to a uniform slip of a rectangular fault shown by a blue rectangle in each panel, in which the slip vector is indicated by a blue arrow.

\section{Abbreviations}

SSE: slow slip events; GNSS: Global Navigation Satellite System; GEONET: GNSS earth observation network system; Hi-net: high-sensitivity seismograph network; PH: Philippine Sea plate; JMA: Japan Meteorological Agency.

\section{Acknowledgements}

We used tilt records from the Kishu observatory operated and preserved by the Disaster Prevention Research Institute, Kyoto University through its collaborative research program. Kensuke Onoue and Yoshinobu Hoso made instructions on how the tilt signals were recorded on bromide papers. We used the unified hypocenter catalog provided by JMA. We thank two anonymous reviewers and the editor Takuya Nishimura for providing us fruitful comments to improve the manuscript. Figures were generated using the Generic Mapping Tools (GMT) software (Wessel and Smith 1998).

\section{Authors' contributions}

MK conducted the forward modeling and prepared the manuscript. YK designed this study, processed the historical bromide tilt records and converted them to digital data. Both authors discussed the results. Both authors read and approved the final manuscript.

\section{Funding}

This work was partly supported by the JSPS KAKENHI Grant Number JP15K17743 in Grant-in-Aid for Young Scientists (B), JP18K03796 in Grant-inAid for Scientific Research (C), JP16H06474, JP19H04620 in Scientific Research on Innovative Areas "Science of Slow Earthquakes," and JST CREST Grant Number JPMJCR1763, Japan. This work was also supported by the Ministry of Education, Culture, Sports, Science and Technology (MEXT) of Japan, under its Earthquake and Volcano Hazards Observation and Research Program.

\section{Availability of data and materials}

The tilt records used in this study are available by contacting the authors. Fault models used in this study (Nishimura et al. 2013) were downloaded via the "Slow Earthquake Database" (Kano et al. 2018) supported by JSPS KAKENHI Grant Number JP16H06472 in Scientific Research on Innovative Areas "Science of Slow Earthquakes."

\section{Ethics approval and consent to participate}

Not applicable.

\section{Consent for publication \\ Not applicable.}

\section{Competing interests}

The authors declare that they have no competing interests.

\section{Author details}

${ }^{1}$ Graduate School of Science, Tohoku University, 6-3, Aramaki-aza-aoba, Aoba-ku, Sendai 980-8578, Japan. ${ }^{2}$ Earthquake Research Institute, The University of Tokyo, 1-1-1, Yayoi, Bunkyo-ku, Tokyo 113-0032, Japan.

Received: 3 May 2019 Accepted: 23 August 2019

Published online: 03 September 2019

\section{References}

Alba S, Weldon RJII, Livelybrooks D, Schmidt DA (2019) Cascadia ETS events seen in tidal records (1980-2011). Bull Seismol Soc Am 109(2):812-821. https://doi.org/10.1785/0120180218

Ando M (1975) Source mechanisms and tectonic significance of historical earthquakes along the Nankai Trough, Japan. Tectonophysics 27(2):119140. https://doi.org/10.1016/0040-1951(75)90102-X

Graham S, DeMets C, Cabral-Cano E, Kostoglodov V, Walpersdorf A, Brudzinski NCM, McCaffrey R, Salazar-Tlaczaniet L (2014) GPS constraints on the 2011-2012 Oaxaca slow slip event that preceded the 2012 March 20 Ometepec earthquake, southern Mexico. Geophys J Int 197(3):15931607. https://doi.org/10.1093/gji/ggu019

Harrison JC (1976) Cavity and topographic effects in tilt and strain measurement. J Geophys Res 81(B):319-328. https://doi.org/10.1029/JB081i002p 00319

Hirose H, Hirahara K, Kimata F, Fujii N, Miyazaki S (1999) A slow thrust slip event following the two 1996 Hyuganada earthquakes beneath the Bungo Channel, southwest Japan. Geophys Res Lett 26(21):3237-3240. https:// doi.org/10.1029/1999GL010999

Ito Y, Hino R, Kido M, Fujimoto H, Osada Y, Inazu D, Ohta Y, linuma T, Ohzono M, Miura S, Mishina M, Suzuki K, Tsuji T, Ashi J (2013) Episodic slow slip events in the Japan subduction zone before the 2011 Tohoku-Oki earthquake. Tectonophysics 600:14-26. https://doi.org/10.1016/j.tecto .2012.08.022

Kano M, Aso N, Matsuzawa T, Ide S, Annoura S, Arai R, Baba S, Bostock M, Chao K, Heki K, Itaba S, Ito Y, Kamaya N, Maeda T, Maury J, Nakamura M, Nishimura T, Obana K, Ohta K, Poiata N, Rousset B, Sugioka H, Takagi R, Takahashi T, Takeo A, Tu Y, Uchida N, Yamashita Y, Obara K (2018) Development of a slow earthquake database. Seismol Res Lett 89(4):1566-1575. https://doi.org/10.1785/0220180021

Kato A, Obara K, Igarashi T, Tsuruoka H, Nakagawa S, Hirata N (2012) Propagation of slow slip leading up to the 2011 Mw 9.0 Tohoku-Oki earthquake. Science 335:705-708. https://doi.org/10.1126/science.1215141

Kato A, Saiga A, Takeda T, Iwasaki T, Matsuzawa T (2014) Non-volcanic seismic swarm and fluid transportation driven by subduction of the Philippine Sea slab beneath the Kii Peninsula, Japan. Earth Planets Space 66:86. https://doi.org/10.1186/1880-5981-66-86

Kimata F, Hirahara K, Fujii N, Hirose H (2001) Repeated occurrence of slow slip events on the subducting plate interface in the Tokai region, central Japan, the focal region of the anticipated Tokai earthquake $(M=8)$. AGU Fall Meeting Abstracts 82

Kobayashi A, Yamamoto T (2011) Repetitive long-term slow slip events beneath the Bungo Channel, southwestern Japan, identified from leveling and sea level data from 1979 to 2008. J Geophys Res 116(B4):B04406. https://doi.org/10.1029/2010JB007822

Luo Y, Liu Z (2019) Slow-slip recurrent pattern changes: perturbation responding and possible scenarios of precursor toward a megathrust earthquake. Geochem Geophy Geosyst 20(2):852-871. https://doi.org/10.1029/2018G C008021

Mashiko N, Yamamoto T, Akutagawa M, Minamoto Y (2013) Digitization of bromide paper records to extract one-minute geomagnetic data. Data Sci J 12:WDS254-WDS257. https://doi.org/10.2481/dsj.WDS-046

Matsumoto K, Sato T, Takanezawa T, Ooe M (2001) GOTIC2: a program for computation of oceanic tidal loading effect. J Geod Soc Jpn 47:243-248

Matsu'ura M, Hasegawa Y (1987) A maximum likelihood approach to nonlinear inversion under constraints. Phys Earth Planet Inter 47:179-187. https:// doi.org/10.1016/0031-9201(87)90076-8

Matsuzawa T, Hirose H, Shibazaki B, Obara K (2010) Modeling short- and longterm slow slip events in the seismic cycles of large subduction earthquakes. J Geophys Res 115(B12):B12301. https://doi.org/10.1029/2010J B007566

Nakagawa H, Toyofuku T, Kotani K, Miyahara B, Iwashita C, Kawamoto S, Hatanaka Y, Munekane H, Ishimoto M, Yutsudo T, Ishikura N, Sugawara Y (2009) Development and validation of GEONET new analysis strategy (version 4). J Geospatial Inf Auth Jpn 118:1-8

Nishimura T (2014) Short-term slow slip events along the Ryukyu Trench, southwestern Japan, observed by continuous GNSS. Prog Earth Planet Sci 1:22. https://doi.org/10.1186/s40645-014-0022-5

Nishimura T, Matsuzawa T, Obara K (2013) Detection of short-term slow slip events along the Nankai Trough, southwest Japan, using GNSS data. J Geophys Res 118(6):3112-3125. https://doi.org/10.1002/jgrb.50222 
Obara K, Kasahara K, Hori S, Okada Y (2005) A densely distributed high-sensitivity seismograph network in Japan: Hi-net by national research institute for earth science and disaster prevention. Rev Sci Instrum 76(2):021301. https://doi.org/10.1063/1.1854197

Okada Y (1992) Internal deformation due to shear and tensile faults in a halfspace. Bull Seismol Soc Am 82(2):1018-1040

Okada Y, Kasahara K, Hori S, Obara K, Sekiguchi S, Fujiwara H, Yamamoto A (2004) Recent progress of seismic observation networks in Japan- - Hinet, F-net, K-NET and KiK-net. Earth Planets Space 56:BF03353076. https:// doi.org/10.1186/BF03353076

Ozawa I (1978) Observation of the crustal movement at Kishu mineobservation by using extensometers. Disas Prevent Res Inst Ann B 21(B-1):113-117

Radiguet M, Perfettini H, Cotte N, Gualandi A, Valette B, Kostoglodov V, Lhomme T, Walpersdorf A, Cano EC, Campillo M (2016) Triggering of the $2014 M_{w} 7.3$ Papanoa earthquake by a slow slip event in Guerrero, Mexico. Nat Geosci 9(11):829-833. https://doi.org/10.1038/ngeo2817

Rogers G, Dragert H (2003) Episodic tremor and slip on the Cascadia subduction zone: the chatter of silent slip. Science 300(5627):1942-1943. https:// doi.org/10.1126/science.1084783

Rousset B, Campillo M, Lasserre C, Frank WB, Cotte N, Walpersdorf A, Socquet A, Kostoglodov V (2017) A geodetic matched filter search for slow slip with application to the Mexico subduction zone. J Geophys Res Solid Earth 122(12):10498-10514. https://doi.org/10.1002/2017JB014448
Ruiz S, Metois M, Fuenzalida A, Ruiz J, Leyton F, Grandin R, Vigny C, Madariaga $\mathrm{R}$, Campos J (2014) Intense foreshocks and a slow slip event preceded the 2014 lquique Mw 8.1 earthquake. Science 345(6201):1165-1169. https:// doi.org/10.1126/science.1256074

Sekine S, Hirose H, Obara K (2010) Along-strike variations in short term slow slip events in the southwest Japan subduction zone. J Geophys Res Solid Earth 115(B9):B00A27. https://doi.org/10.1029/2008JB006059

Szeliga W, Melbourne T, Santillan M, Miller M (2008) GPS constraints on 34 slow slip events within the Cascadia subduction zone, 1997-2005. J Geophys Res 113(B4):B04404. https://doi.org/10.1029/2007JB004948

Tamura Y, Sato T, Ooe M, Ishiguro M (1991) A procedure for tidal analysis with a Bayesian information criterion. Geophys J Int 104:507-516. https://doi. org/10.1111/j.1365-246X.1991.tb05697.X

Tanaka T, Hoso Y, Koizumi M, Kato M (1981) Observation of ground tilts at Kishu Mine. J Geodetic Soc Jpn 27(1):1-10. https://doi.org/10.11366/ sokuchi1954.27.1 (in Japanese with English abstract)

Wessel P, Smith WHF (1998) New, improved version of the Generic Mapping Tools released. EOS Trans Am Geophys Union 79(47):579. https://doi. org/10.1029/98EO00426

\section{Publisher's Note}

Springer Nature remains neutral with regard to jurisdictional claims in published maps and institutional affiliations.

\section{Submit your manuscript to a SpringerOpen ${ }^{\circ}$ journal and benefit from:}

- Convenient online submission

- Rigorous peer review

- Open access: articles freely available online

- High visibility within the field

- Retaining the copyright to your article

Submit your next manuscript at $\boldsymbol{\nabla}$ springeropen.com 